\title{
Percepción de una marca amor. Caso de la Universidad Nacional de Colombia
}

\section{Perception of a love brand. Case of the National University of Colombia}

\author{
DOI: https://doi.org/10.17981/econcuc.40.2.2019.08
}

Artículo de investigación. Fecha de recepción: 30/10/2018 Fecha de aceptación: 15/08/2019

\author{
Luz Alexandra Montoya-Restrepo \\ Universidad Nacional de Colombia. (Medellín, Colombia) \\ alexandra.montoya@gmail.com \\ Javier A. Sánchez-Torres \\ Universidad de Medellín. (Medellín, Colombia) \\ jasanchez@udem.edu.co \\ Sandra Patricia Rojas-Berrio \\ Universidad Nacional de Colombia. (Bogotá, Colombia) \\ sprojasb@unal.edu.co \\ Juan Manuel Castaño-Molano \\ Universidad Nacional de Colombia. (Manizales, Colombia) \\ jmcastanom@unal.edu.co \\ Ivan Alonso Montoya-Restrepo \\ Universidad Nacional de Colombia. (Medellín, Colombia) \\ iamontoyar@unal.edu.co
}

Para citar este artículo:

Montoya-Restrepo, L., Sánchez-Torres, J., Rojas-Berrio, S., Castaño-Molano. J. y Montoya-Restrepo, I. (2019). Percepción de una marca amor. Caso de la Universidad Nacional de Colombia. Económicas CUC, 40(2), 117-138. DOI: http://dx.doi.org/10.17981/ econcuc.40.2.2019.08

\section{Resumen}

El posicionamiento de una marca es uno de los principales elementos que distingue a una organización de otra y es por ello que el presente documento analiza la valoración de una love mark $^{\circledR}$ o marca amor, definido como el vínculo emocional del consumidor con su marca, en especial, en el caso de una institución muy reconocida en el ámbito de los colombianos como es la Universidad Nacional (Colombia), con más de 150 años de tradición. El método utilizado fue la aplicación del índice desarrollado por Eunjoo Cho en 2011, quien desarrolla una metodología para la evaluación de marcas amor adaptada al contexto educativo. Se realizó mediante encuestas online a 267 personas con técnica mixta (cualitativa-cuantitativa) por valoración de escala de Likert. Los resultados corroboran que el programa gubernamental "ser pilo paga" ha afectado significativamente a las universidades públicas del país, puesto que este paga al estudiante sus estudios con un crédito condonable en la universidad que éste decida cursar sus carreras profesionales. Las conclusiones se centran en la posibilidad de posicionar una marca, a pesar de ser una universidad pública, como una marca reconocida, recordada, posicionada y finalmente como marca amor en los colombianos.

Palabras clave: Love mark; educación; posicionamiento de marca

\begin{abstract}
The positioning of a brand is one of the main elements that distinguishes one organization from another and that is why this document analyzes the valuation of a love mark ${ }^{\circledR}$ or love brand, defined as the emotional bond of the consumer with their brand. especially, in the case of a highly recognized institution in the field of Colombians such as the National University (Colombia), with more than 150 years of tradition. The method used was the application of the index developed by Eunjoo Cho in 2011, who developed a methodology for the evaluation of love marks adapted to the educational context. It was carried out through an online survey of 267 people with mixed technique (qualitative-quantitative) by Likert scale assessment. The results corroborate that the government program "be pilo pays" has significantly affected the country's public universities, since it pays the student for his studies with a forgivable credit in the university that he decides to pursue his professional careers. The conclusions focus on the possibility of positioning a brand, despite being a public university, as a recognized, remembered, positioned brand and finally as a love brand in Colombians.
\end{abstract}

Keywords: Love mark; education; brand positioning

JEL: M3 Marketing and Advertising

D11 Consumer Economics: Theory

D4 Market Structure, Pricing, and Design 


\section{INTRODUCCIÓN}

La culminación de la segunda guerra mundial trajo consigo un nuevo orden mundial transformando así las nuevas reglas de juegos organizacionales (González, Galeano y Trejos, 2015, p. 80), generándose nuevas exigencias sociales para con las empresas, donde la mera producción de su bien o prestación de su servicio resulta poca cosas (Chumaceiro, Hernández y Chirinos, 2016), así pues, las últimas décadas se "han caracterizado por cambios vertiginosos desde perspectivas políticas, económicas, sociales y de mercado, que obligan a las organizaciones a emprender nuevas maneras de hacer las labores" (Villasmil y Crisien, 2015, p. 246), como expresan Chumaceiro, Hernández, Meléndez y Acurero (2017) "estos cambios han derivado en nuevas formas de producción, intercambio y conexión globalizada; así como una reorganización y concepción de las prácticas" (pp. 201-202), de marketing que deben ayudar a las organizaciones para diferenciarse del resto.

Es así como el posicionamiento de una marca es uno de los principales elementos diferenciadores que tiene una empresa para lograr alcanzar sus objetivos de marketing, la misma definición de marca corresponde a una "identificación única" que diferencia de los competidores, proporcionando confianza en el producto (Munuera, 2001), la calidad o su precio (Gallo, 2000; Hernani, 2008; Blackett y Harrison, 2001) y el proceso de compra, desde el interés hasta el posconsumo permite un aprendizaje en el consumidor que facilita la posterior decisión de compra, disminuyendo el tiempo de la decisión (Keller \& Kotler, 2016).

Estos aspectos diferenciadores del producto con respecto a la marca permiten a los consumidores relacionar la experiencia previa con un consumo posterior (Aaker $\&$ Biel, 2013), estas comparaciones se encuentran en la experiencia y en los valores que el cliente obtiene del proceso por esto algunos investigadores le han asignado dimensiones de personalidad y emocionalidad (Haigood, 2001, Escobar-Farfán, Mateluna y Araya, 2006).

Kotler (2001) propone una definición comercial de marca: "Es un nombre, símbolo o diseño, o una combinación de ellos, cuyo propósito es designar los bienes o servicios de un fabricante o grupo de fabricantes, y diferenciarlos del resto de los productos y servicios de otros competidores" (p. 404).

Las marcas aportan a los consumidores opciones claras con la libertad para su elección, proporcionan certidumbre de calidad y generar una seguridad psicológica mayor reduciendo el riesgo de elegir incorrectamente todos estos atributos se denominan el "valor intangible de la marca" (Alvarado \& Lucano, 2015) encargado de llevar la preferencia de estas (Temporal y Lee, 2003). Esta confianza del consumidor se convierte en lealtad en las decisiones de recompra lo que se convierte en una ventaja de las compañías disminuyendo incluso sus costos de mercadeo (Delgado, Ballester y Peláez, 2014; Colmenares y Saavedra, 2007).

Pero la marca va más allá, ya que produce transferencias en sus significados, incluso hasta la posibilidad de construir una propia personalidad a partir de la marca (Schembri, Merrilees y Kristiansen, 2010), establecen relaciones emocionales con la misma y con los precios asociados a esta (Park, Eisingerich, Pol \& Park, 2013) y es por esta razón por la que tantas empresas están en el negocio de la creación, fortalecimiento y gestión de las marcas (Martínez, 2014). 
Con el tiempo esta "emocionalidad" que se la ha otorgado a las marcas ha llevado al estudio de la intimidad y el sentimentalismo que los consumidores desarrollan con la misma. En el presente documento se describirá el concepto de "marca- Amor" o Love- mark ${ }^{\circledR}$ para analizarlo en una de las instituciones más queridas de Colombia como lo es la Universidad Nacional.

TABLA 1.

Principales escalas de la medición de marca

\section{La Importancia de la marca dentro de la organización}

Como se puede observar la marca se convierte en uno de los elementos intangibles más importantes y mejor valorados por las organizaciones, buscando diferentes alternativas para su medición y consolidación, como por ejemplo (Tabla 1):

\begin{tabular}{ll}
\hline \multicolumn{1}{c}{ Concepto } & \multicolumn{1}{c}{ Definición } \\
\hline Brand & Grado en el que el consumidor usa el \\
Dependence & nombre de marca (Martínez, 2014) \\
(Dependencia de & para tomar su decisión de compra \\
la marca) & (Bristow, Schneider \& Schuler, 2002).
\end{tabular}

Brand Love

(Amor a la marca, pasión por la marca)
Vínculo emocional del consumidor satisfecho con un determinado nombre comercial (Carroll \& Ahuvia, 2006, García, 2016).
Brand

Consciousness

(Conciencia de la marca)

Brand

Relevance

(Relevancia de la marca)
Orientación hacia la compra de marcas nacionales más caras y conocidas

Relevancia de (nombre de) la marca en el proceso de elección de un producto dentro de una categoría de producto (Hammerschmidt \& Donnevert, 2007).
Brand Love Scale (Carroll \& Ahuvia, 2006). Brand Love Scale (Thomson, MacInnis \& Park, 2005), Proponen una escala basada en el afecto y la pasión, dos elementos psicológicos del amor (Batra, Ahuvia \& Bagozzi, 2012). Cho (2011). Carroll y Ahuvia (2006) en su Brand Love Scale, proponen una escala de amor de marca que consta de 10 elementos en los que evalúa si la marca se comporta como una maravilla, lo hace sentir bien, es increíble, me hace muy feliz, la amo, soy apasionado y apegado de la marca, y unos ítems en donde no me interesa la marca, o no me produce ninguna emoción. Thomson, MacInnis \& Park (2005). La escala evalúa la pasión y el afecto, pero no presenta la conexión o el apego, ni la intimidad, dimensiones: afecto y pasión.

Lee, Kim, Pelton, Knight \& Forney (2008)

Consumer Styles Inventory (Sproles

\& Sproles, 1990).

Brand Relevance Scale (Chernev, Hamilton \& Gal, 2011). Brand Relevance Scale (Hammerschmidt \& Donnevert, 2008). 


\begin{tabular}{|c|c|}
\hline $\begin{array}{l}\text { Brand } \\
\text { Awareness } \\
\text { (Reconocimiento } \\
\text { de la marca) }\end{array}$ & $\begin{array}{l}\text { Probabilidad de que un nombre } \\
\text { de marca surja en la mente del } \\
\text { consumidor (Keller, 2008; 1993). }\end{array}$ \\
\hline $\begin{array}{l}\text { Perceived } \\
\text { quality } \\
\text { (Calidad } \\
\text { Percibida) }\end{array}$ & $\begin{array}{l}\text { Concebida para medir la calidad de } \\
\text { productos tangibles, mientras que se } \\
\text { propone medir el capital de marca de } \\
\text { una marca con elementos compuesto } \\
\text { de producto tangible y servicio } \\
\text { intangible. }\end{array}$ \\
\hline $\begin{array}{l}\text { Brand } \\
\text { personality } \\
\text { (Personalidad de } \\
\text { marca) }\end{array}$ & $\begin{array}{l}\text { Yoo \& Donthu (2001) utilizaron los } \\
\text { rasgos definidos por Aaker (1992; } \\
\text { 1996; 2007) para desarrollar un } \\
\text { modelo de personalidad de marca }\end{array}$ \\
\hline
\end{tabular}

Grado de compromiso, nivel de recompra y precio primado. Este grupo se fijó sobre la base conceptual de que el precio superior es el Brand loyalty (Lealtad de marca) indicador básico que demuestra la lealtad, ya que significa la cantidad que el consumidor estaría dispuesto a pagar por un producto en comparación con los productos similares disponibles (Chernatony y McDonald, 2003).
Lambin \& Tesser (2004) proponen medir el reconocimiento de marca a través de los indicadores: conocimiento de la marca, recordación y reconocimiento (Çifci et al, 2016).

Escala original de Yoo y Donthu (2001)

Modelo Servqual (Andreassen et al, 2016).

La lista de rasgos quedó conformada por tres grupos: comunes en todos estudios (atrevido, divertido, chévere, moderno, orientado a la familia, sincero, confiable, seguro de sí mismo, femenino, masculino y fuerte de carácter), comunes en al menos dos estudios (sofisticado, amigable, tranquilo, tímido, pacífico, elegante, violento y juvenil) y propios del estudio de España (impulsivo, apasionado y emocional).

Fung So, King, Sparks \& Wang (2016), Pritchard \& Howard (2015), Malik \& Guptha (2013).
La marca entonces deja de ser un símbolo para convertirse en elemento de relación con el consumidor y obliga a las organizaciones a trabajar en valores como la notoriedad, personalidad, calidad percibida y la lealtad (Alvarado \& Lucano, 2015, p. 29). Muchas son las dimensiones que pueden evaluarse en la marca, como los propuestos por Aaker (1997) o el estudio de Escobar- Farfán, Mateluna y Araya (2016). La Tabla 2 demuestra como uno de estos elementos es la emocionalidad, pilar fundamental de la Love mark $₫$ que se verá a continuación. 
TABLA 2.

Dimensiones de la marca

\begin{tabular}{|c|c|c|}
\hline $\begin{array}{l}\text { Dimensiones de } \\
\text { Aaker (1991) }\end{array}$ & Últimos estudios presentes & $\begin{array}{c}\text { Frecuencia } \\
\text { relativa }\end{array}$ \\
\hline Sinceridad & $\begin{array}{l}\text { Pirela et al. (2004); Rojas-Méndez et al. (2004); Colmenares } \\
\text { y Saavedra (2008); Saavedra et al. (2008); Denegri } \\
\text { et al. (2009); Olavarrieta et al. (2010); Toldos (2012); } \\
\text { Goñi et al. (2013); Denegri et al. (2013); Araya-Castillo } \\
\text { y Etchebarne (2014); García et al. (2014); Araya-Castillo } \\
\text { y Escobar-Farfán (2015); Araya-Castillo et al. (2016) }\end{array}$ & $66.7 \%$ \\
\hline Emocionalidad & $\begin{array}{l}\text { Pirela et al. (2004); Rojas-Méndez et al. (2004); Colmenares y } \\
\text { Saavedra (2008); Saavedra et al. (2008); Denegri et al. (2009); } \\
\text { Olavarrieta et al. (2010); Goñi et al. (2013); Denegri et al. (2013); } \\
\text { Araya-Castillo y Etchebarne (2014); García et al. (2014); Araya- } \\
\text { Castillo y Escobar-Farfán (2015); Araya-Castillo et al. (2016). }\end{array}$ & $66.7 \%$ \\
\hline Competencia & $\begin{array}{l}\text { Rojas-Méndez et al. (2004); Denegri et al. (2009); Olavarrieta et al. } \\
\text { (2010); Goñi et al. (2013); Denegri et al. (2013); Araujo et al. (2013); } \\
\text { Araya-Castillo y Etchebarne (2014); García et al. (2014); Araya- } \\
\text { Castillo y Escobar-Farfán (2015); Araya-Castillo et al. (2016). }\end{array}$ & $55.6 \%$ \\
\hline Sofisticación & $\begin{array}{l}\text { Rojas-Méndez et al. (2004); Denegri et al. (2009); Olavarrieta et al. } \\
\text { (2010); Toldos (2012); Muller y Zancan (2013); Goñi et al. (2013); } \\
\text { Araya-Castillo y Etchebarne (2014); Araya-Castillo y Escobar- } \\
\text { Farfán (2015). }\end{array}$ & $44.4 \%$ \\
\hline Rudeza & $\begin{array}{l}\text { Pirela et al. (2004); Olavarrieta et al. (2010); Toldos (2012); Goñi et } \\
\text { al. (2013); Araya-Castillo y Etchebarne (2014); García et al. (2014); } \\
\text { Araya-Castillo y Escobar-Farfán (2015). }\end{array}$ & $38.8 \%$ \\
\hline
\end{tabular}

Fuente: Escobar-Farfán, Mateluna y Araya, 2016, p. 107.

En este contexto de posicionamiento de marca, la relación de las marcas con los consumidores se hace tan cercana que se puede decir que los consumidores "aman" sus marcas, sienten profundo cariño y anhelo por ellas, hasta el punto de extrañarlas cuando desaparecen. Esta cercanía emocional ha sido analizada por el neuromarketing, en donde se descubren centros de activación con los productos y sus marcas cercanas al sentimiento amoroso y además que generan sustancias de amor como la dopamina (Lindstrom, 2011) es en estos análisis que es posible hablar de marcas amor o marcas pasión.

\section{Love Marks}

Para Roberts (2005; 2006) los consumidores son ante todo "seres emocionales" (Roberts, 2005, p. 42), el autor propone que las marcas para seguir cumpliendo su objetivo "creen vínculos emocionales profundos y complejos" lo que denomina una Lovemark ${ }^{\circledR}$ (Kelemen, 2013), las cuales se basan en "crear una relación personal, una historia de Amor con la gente, son creativas y están envueltos en misterio, con un toque de sensualidad" (p. 70). Roberts y su equipo identifican tres atributos fundamentales para que las Lovemark (Albert, Merunka \& Valette-Florence, 
2008) desarrollen "su especial resonancia emocional": el misterio, la intimidad y la sensualidad (Antequera \& Lopes, 2016, p. 6).

Para la presente investigación se tendrá como una Marca Amor o Love Mark ${ }^{\circledR}$ como el vínculo emocional del consumidor con una marca específica, que le proporciona satisfacción y sobre la cual manifiesta alta lealtad (Carroll \& Ahuvia, 2006; García, 2016).

Bagozzi, Batra \& Ahuvia (2014) proponen tres elementos para desarrollar las marcas amor: Comportamientos basado en la pasión, integración de la marca y el ajuste intuitivo que se observan en la Figura 1, con sus variables.

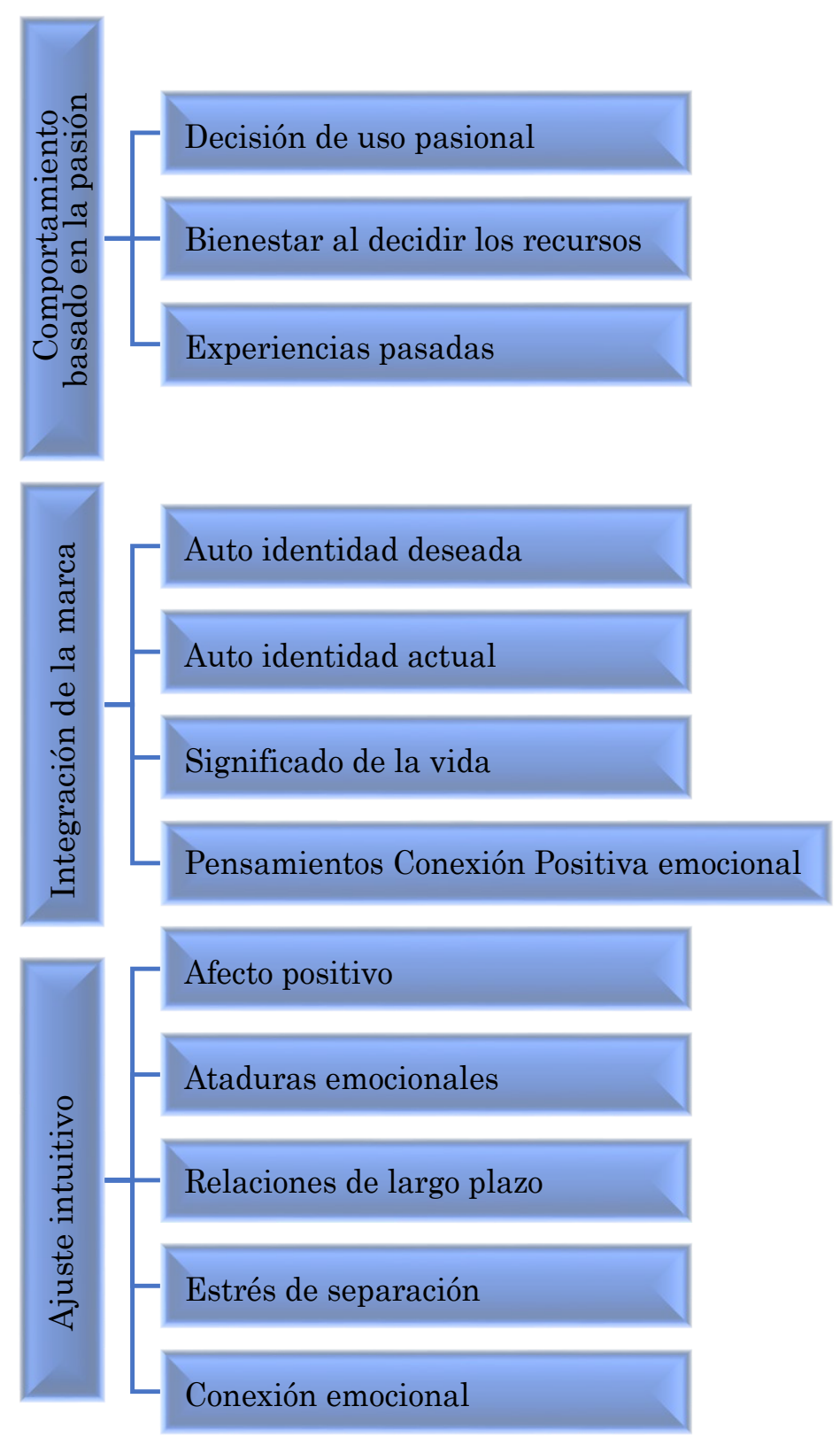

Figura 1. Variables de una Lovemark Fuente: Bagozzi, Batra \& Ahuvia, 2014. p. 4.
La consolidación de una Lovemark se fundamenta en dos elementos indispensables: el respeto y el amor. El respeto se centra en la confiabilidad del producto o servicio y es por ello por lo que sus características deben mantener un estándar de la más alta calidad, así como la confianza y la reputación, las cuales se deben mantener en el mismo nivel compra tras compra. Adicionalmente requiere amor, el amor se divide en tres componentes como son el misterio, la sensualidad y la intimidad. El misterio permite contar grandes historias que involucran el pasado, presente y futuro, así como sueños, mitos, íconos e inspiración; la sensualidad recurre al uso de los sentidos, y la intimidad es la suma de empatía, compromiso y pasión. En resumen, su teoría establece que una Lovemark mantiene una relación con el consumidor unida por amor (Carroll \& Ahuvia, 2006), Ahuvia, 2005), dicha relación es personal y única (Forero. 2014, p. 6). Según Roberts (2004; 2005; 2006), estas tres dimensiones de imagen de marca contribuyen positivamente (Pavel, 2013) a la creación de una experiencia Lovemark (Bagozzi, Batra \& Ahuvia, 2017), que conduce los consumidores a convertirse en ávidos fanáticos de una determinada oferta de una empresa, estos atributos se observan en la Figura 2.

Los autores diferencian el posicionamiento de marca con el lovemark ${ }^{\circledR}$ por el grado de aceptación y vinculo que tienen los clientes con la empresa y sus marcas, proponiendo el nivel más bajo de reconocimiento de una marca como una marca silenciosa y en el que el nivel de cercanía de la marca hace que los consumidores sientan lealtad de tal forma que no evalúen de manera sistemática sus características sino que la prefieran por la alta confianza y relación íntima con la misma, hasta el punto de señalar que la necesitan y la aman sinceramente (Figura $3)$. 

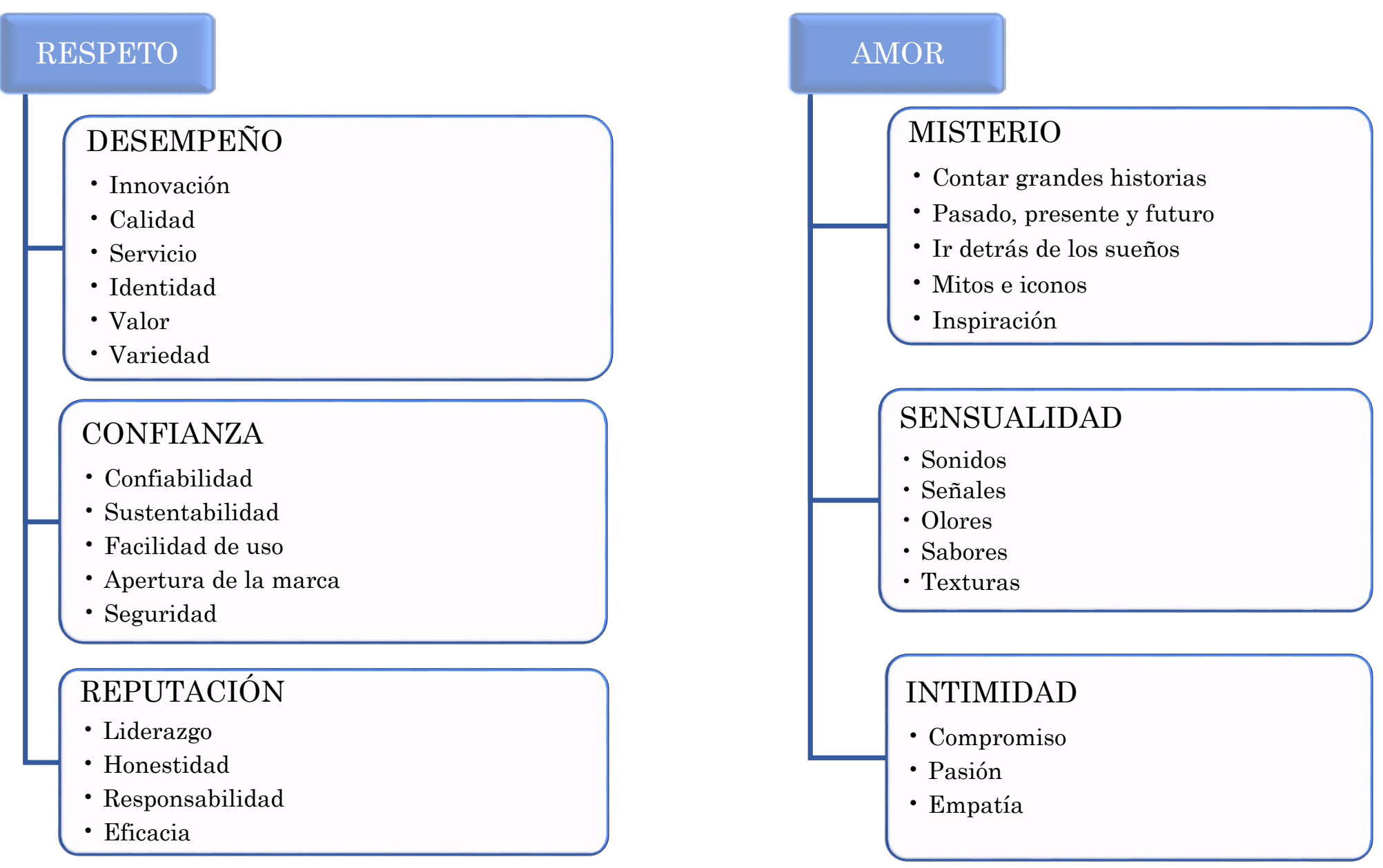

Figura 2. Atributos Lovemarks.

Fuente: Elaboración propia.

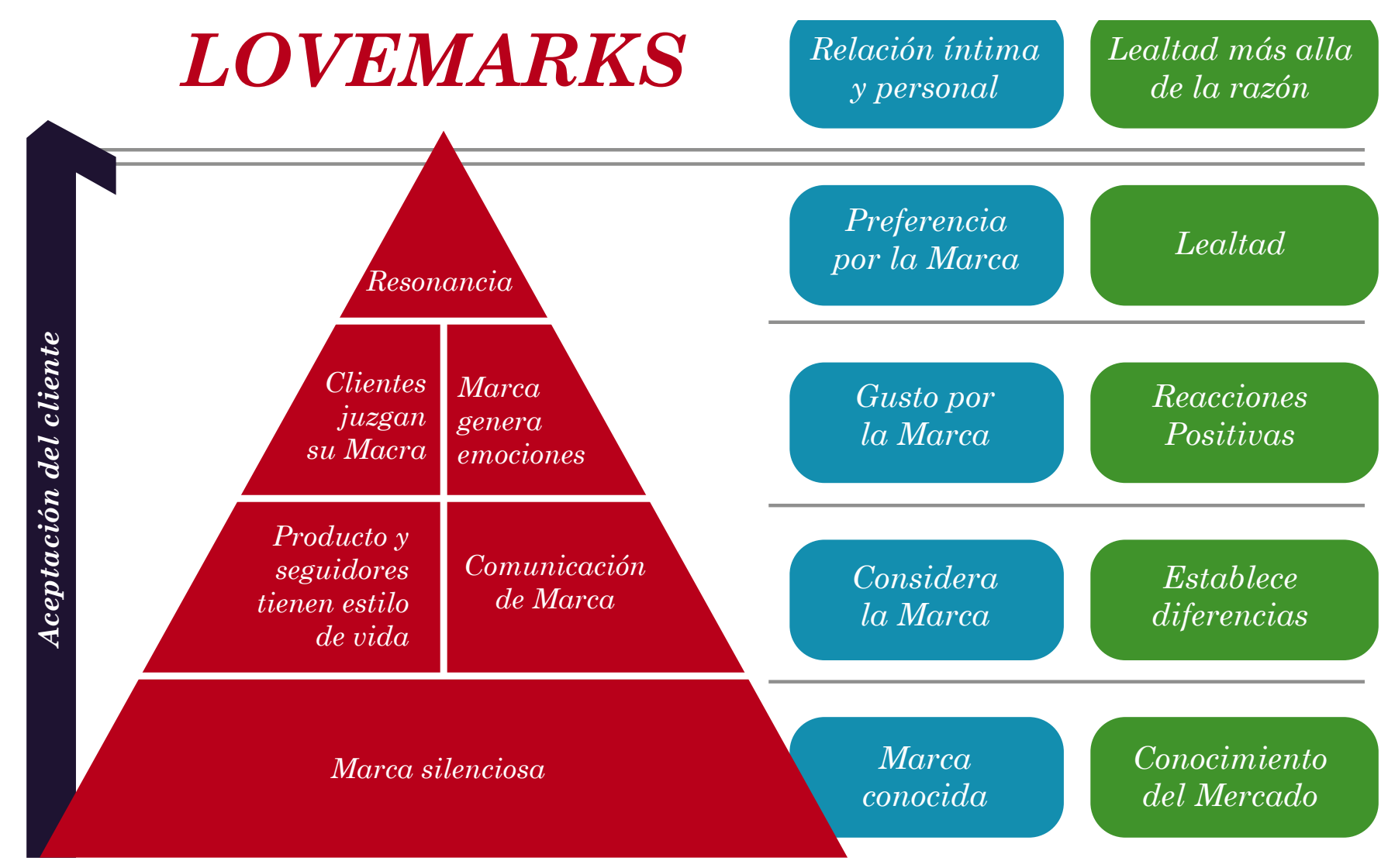

Figura 3. Pirámide de reconocimiento de los clientes de una Lovemark.

Fuente: Elaboración propia. 
Para instrumentalizar los constructos y las variables definidos en la Lovemark se presenta el trabajo de Montoya, Montoya y
Castaño (2016), en el cual se definen cada una de las características del amor y el respeto que señala Roberts (2005):

TABLA 3.

\section{Definiciones de constructos y variables de la Lovemark}

\begin{tabular}{|c|c|c|}
\hline Constructo & Variables & Definición \\
\hline \multirow{5}{*}{ Misterio } & $\begin{array}{l}\text { Grandes } \\
\text { historias }\end{array}$ & $\begin{array}{l}\text { Capacidad de la marca de construir grandes leyendas acerca del desarrollo de } \\
\text { esta y del producto y sus fundadores, ellos permiten mejor recordación en la } \\
\text { mente del consumidor, se puede reconocer en marcas como Bavaria (Arbeláez, } \\
\text { \& Sandoval, 2008), ego (Lindstrom, 2012), Jack Danield's (Salinas et al, 2000) } \\
\text { y Malboro (Bassat, 2006), entre otras. }\end{array}$ \\
\hline & $\begin{array}{l}\text { Pasado, presente } \\
\text { y futuro }\end{array}$ & $\begin{array}{l}\text { Relacionado directamente con la historia de la marca, su posición actual y el } \\
\text { modelo prospectivo que propende. Las marcas posicionadas colombianas se } \\
\text { caracterizan por tener una supervivencia mayor de } 10 \text { años en el mercado. Es } \\
\text { la historia detrás de la marca. Por ejemplo, Ramo (Martínez, 2014) y Fruco } \\
\text { (Ortega, 2012), entre otras. }\end{array}$ \\
\hline & Nutre de sueños & $\begin{array}{l}\text { La capacidad de cumplir con las expectativas emocionales de los clientes, como } \\
\text { marcas de lujo tales como Rolex (Pol, 2012), BMW (Hatch \& Schultz, 2010), } \\
\text { Harley Davidson (Holt, 2004). }\end{array}$ \\
\hline & $\begin{array}{l}\text { Ingredientes } \\
\text { secretos }\end{array}$ & $\begin{array}{l}\text { El misterio es uno de los ingredientes fundamentales de las marcas, se trata } \\
\text { de no contar todo acerca de la marca y dejar al consumidor con un toque } \\
\text { de intriga respecto de esta, para poder tener la capacidad de sorprenderlo } \\
\text { cada vez más, las fórmulas secretas funcionan muy bien, tal como Coca-Cola } \\
\text { (Pendergrast, 2001). }\end{array}$ \\
\hline & Mitos & $\begin{array}{l}\text { Son las historias que se tejen detrás de las empresas, sus fundadores y sus } \\
\text { leyendas. Mitos importantes se encuentran en el fundador de Bavaria Leo } \\
\text { Koop (Valero, 1999), a quien puede pedírsele favores en su tumba, Xerox con } \\
\text { su banano de oro (Montoya et al, 1994) o Apple y su fundador Steve Jobs } \\
\text { (Maneiro, 2011). }\end{array}$ \\
\hline \multirow{5}{*}{ Sentidos } & Ver & $\begin{array}{l}\text { El sentido por excelencia y en el cual el marketing tradicional ha } \\
\text { fundamentado su experiencia, estudios recientes demuestran que conjugado } \\
\text { con otros sentidos (Hultén, 2011). }\end{array}$ \\
\hline & Oler & $\begin{array}{l}\text { El olfato es el sentido más vinculado con las emociones, y al estar directamente } \\
\text { relacionado con el cerebro límbico se vincula con el recuerdo y la evocación. } \\
\text { Este sentido se puede desarrollar en el consumidor a través del marketing } \\
\text { olfativo (Cantalapiedra, 2006, Sánchez, 2006). }\end{array}$ \\
\hline & Escuchar & $\begin{array}{l}\text { La música es uno de los mayores componentes del estado de ánimo, de tal } \\
\text { forma que permite fortalecer los lazos emocionales (Sánchez 2006). Es así como } \\
\text { los sonidos pueden evocar una marca, por ejemplo, el posicionamiento de Nokia } \\
\text { con su ringtone (Chikezie, 2011). }\end{array}$ \\
\hline & Tocar & $\begin{array}{l}\text { Otro importante sentido, cuando un consumidor quiere una prenda de vestir lo } \\
\text { primero que busca es tocar la textura de la tela, así con muchos productos, en } \\
\text { los cuales se hace indispensable la sensación del producto en las manos. Esto } \\
\text { especialmente puede verificarse con alimentos, en frutas y verduras. }\end{array}$ \\
\hline & Saborear & $\begin{array}{l}\text { Finalmente, el ultimo sentido es percibir las cosas con el sabor y el cual será } \\
\text { fundamental para decidir productos o servicios, la guerra de las colas, durante } \\
\text { el reto Pepsi, se centró en el mejor sabor de Pepsi en un sorbo frente a Coca- } \\
\text { Cola (Lehrer, 2006; Capparell, 2007). }\end{array}$ \\
\hline
\end{tabular}


$\cdots$

\section{Cercanía}

Emoción y recompensa

Empatía

Intimidad

(Love Mark)

CIM

Inspiración

Conciencia-

Conocimiento

Asociación

Innovación

Calidad

Desempeño

(Love Mark)

y Calidad

(Brand

Servicio

equity)
Es la capacidad que tiene la empresa de comunicarse con el consumidor, de tener contacto y proximidad, de tal forma que el consumidor sienta que es escuchado y que sus opiniones y deseos son valorados por la empresa. Cada vez más posible con las comunicaciones virtuales.

Una marca preferida crea una sensación de felicidad por la dopamina que permite tener felicidad, de allí la importancia de las marcas de lujo que se basan en la dificultad de adquirirlas y el placer no sólo de tenerlas sino de exhibirlas. La recompensa llega por el esfuerzo realizado para poder conseguir el objeto deseado.

Cuando una marca es atractiva, interesante y coherente, permite desarrollar la empatía, definida como la capacidad de conectar la marca con el consumidor a través del sentimiento, esta conexión permite que las personas puedan sentir felicidad, así como se puede observar en las neuronas espejo, que permiten a las personas y algunos animales ponerse en la situación de otros (Rizzolatti \& Giner, 2006). La empatía de una marca con su público permite desarrollar un sentimiento de admiración y deseo.

Conectarse con los valores y aspiraciones de los consumidores garantiza su identificación plena y en consecuencia su lealtad, si las marcas pueden despertar un sentimiento, y permitir que las personas se sientan orgullosas y le sigan, logran transmitir esta inspiración.

Uno de los retos más importantes es la comunicación con la marca, tener interés en aprender de la marca y conocerla para luego tomar decisiones con respecto a ella, es el paso fundamental para lograr su posicionamiento, encontrar la forma de llamar la atención, y posterior recordación es uno de los elementos fundamentales de la estrategia de comunicación con los clientes.

La capacidad de encontrar relaciones entre la marca, las necesidades, los deseos e intereses de los consumidores, hace que las marcas se fortalezcan, de la capacidad de aprendizaje de ellos, será también su capacidad de toma de decisiones cuando requieran buscar una opción en los cuales se encuentra la marca que se quiere posicionar.

Los consumidores siempre buscan algo nuevo, la capacidad de innovación es una de las principales herramientas que tienen las empresas para ser competitivas (Monferrer, 2013, Ripoll, \& Oliver, (2014). Esta capacidad de innovación no sólo debe centrarse en la mejor satisfacción de necesidades, sino también en la capacidad de sorprender e inspirar a los consumidores, éxito que tuvo en sus principios por ejemplo la marca Apple (Maneiro, 2011) y Disney (Thomke \& Randal, 2014).

Definida como la satisfacción de las exceptivas del cliente. Lo mínimo que espera un consumidor de una buena marca es que tenga todos los atributos de calidad que espera.

Así como la calidad, las marcas posicionadas tienen una óptima promesa de servicio y la cumplen, de tal manera que los clientes se sientan satisfechos con sus marcas.

Una marca de excelente desempeño tiene la capacidad por sí sola de diferenciarse de otras y de esta manera los clientes puedan tener criterios de comparación.

Es la equivalencia que hace el consumidor del precio, la calidad, el beneficio percibido, sus anhelos, la satisfacción y el precio de adquisición.

El lugar de origen tiene muchos elementos importantes, el primero está vinculado con la cultura, el segundo con la añoranza, un tercero con las calidades de materias primas y con las costumbres de uso del producto (Fernández, 2014, Torres et al, 2014). 


\begin{tabular}{|c|c|c|}
\hline \multirow{5}{*}{$\begin{array}{l}\text { Confianza } \\
\text { (Love Mark) } \\
\text { Lealtad } \\
\text { (Brand } \\
\text { equity) }\end{array}$} & Confiabilidad & $\begin{array}{l}\text { Directamente relacionada con la honestidad de la marca, la confianza en la } \\
\text { misma significa que la promesa de venta se cumplirá y que puedo estar seguro } \\
\text { como atributo de marca que el producto es homogéneo en calidad y que la } \\
\text { respuesta se mantendrá en el transcurso del tiempo. }\end{array}$ \\
\hline & Compromiso & $\begin{array}{l}\text { Es el cumplimiento de la palabra dada, en este sentido está estrechamente } \\
\text { enlazado con la confiabilidad. Es la expectativa de esperar que el producto } \\
\text { cumpla con los requerimientos y la expectativa que fue creada. }\end{array}$ \\
\hline & Facilidad & Entendimiento que tiene el consumidor de la marca y del producto o el servicio. \\
\hline & Lealtad & $\begin{array}{l}\text { Es el compromiso de defender aquello que se cree, preferirlo y mantener una } \\
\text { relación que no cambia en el tiempo, significa que el consumidor preferirá } \\
\text { la marca aun cuando el mercado le presente otras opciones. Es uno de los } \\
\text { resultados que se buscan cuando se construye una marca. }\end{array}$ \\
\hline & $\begin{array}{l}\text { Elasticidad de } \\
\text { Precio }\end{array}$ & $\begin{array}{l}\text { Es la respuesta de los consumidores cuando un producto cambia de precio, en } \\
\text { general las marcas posicionadas tienen una elasticidad baja (inelasticidad), es } \\
\text { decir que no cambian sus demandas por cambios pequeños en el precio. }\end{array}$ \\
\hline $\begin{array}{l}\text { Reputación } \\
\text { (Love Mark) }\end{array}$ & $\begin{array}{l}\text { Liderazgo } \\
\text { (Dominación de } \\
\text { la conciencia de } \\
\text { marca) }\end{array}$ & $\begin{array}{l}\text { Las marcas posicionadas son líderes, se comportan como top of mind (primeros } \\
\text { en la mente del consumidor) top of heart (primeros en el corazón) y son los } \\
\text { primeros que se buscan (top of find). Significa la lealtad de los consumidores } \\
\text { los lleva a preferirlas por encima de otros criterios frente a su competencia. }\end{array}$ \\
\hline $\begin{array}{l}\text { Asociaciones } \\
\text { de marca } \\
\text { (Brand } \\
\text { Equity) } \\
\text { Conciencia de } \\
\text { Marca }\end{array}$ & $\begin{array}{l}\text { Honestidad y } \\
\text { Responsabilidad } \\
\text { empresarial }\end{array}$ & $\begin{array}{l}\text { La capacidad organizacional de compartir su misión, visión y valores } \\
\text { corporativos con los miembros de la sociedad en general. Las marcas dependen } \\
\text { directamente de la imagen que tienen de ellos los consumidores, por eso } \\
\text { la honestidad y la responsabilidad empresarial son vitales al momento } \\
\text { de mantener la fidelidad de los consumidores. En muchas ocasiones se ha } \\
\text { observado como las empresas han tenido que tomar decisiones fuertes para } \\
\text { mantener sus consumidores, tales como el apoyo a petroleras, el cuidado del } \\
\text { medio ambiente o el trabajo infantil o en condiciones deplorables. }\end{array}$ \\
\hline
\end{tabular}

Fuente: Montoya, Montoya y Castaño, 2016, pp. 21-22.

El concepto marca amor, resulta interesante al permitir entender más allá del producto top of mind (primero en la mente del consumidor) denominando un producto top of heart (primero en el corazón) buscando que sea top of hand (primero en las manos), es decir asequible a las manos del consumidor,

Finalmente Delgado, Ballesteros y Peláez (2014) señalan:

"el amor a la marca se manifiesta en mayor medida entre aquellos individuos para los cuales las marcas son importantes en sus decisiones de compra frente a aquellos otros que no le confieren ninguna. Así mismo, cuanto más hedónicas sean las motivaciones que guían la compra y consumo de los productos en términos de placer, diversión y disfrute, mayores son los niveles de amor que despiertan las marcas" (citado por Ballester, 2004, p. 3).

\section{Caso: Universidad Nacional de Colombia (UN)}

La Universidad Nacional de Colombia es una de las universidades más destacadas en el país, buscando una educación universal e incluyente. Fue creada el 22 de septiembre de 1867 por el Congreso de la República quien le dio el nombre de Universidad Nacional de los Estados Unidos de Colombia, con seis facultades: Artes y Oficios, Derecho, Medicina, Literatura y Filosofía, Ciencias Naturales e Ingeniería al año siguiente bajo la rectoría de Manuel Ancizar, fueron anexados: el Observatorio Astronómico, el Museo Nacional, el Laboratorio Químico Nacional, la Biblioteca Nacional, el Hospital de la Caridad y el Militar. A pesar de dificultades políticas e ideológicas, entre 1903 
y 1940 surgieron en la Universidad más de 20 carreras, como Arquitectura, Enfermería, Farmacia, Ingeniería Química, Medicina Veterinaria, Odontología y Química, logrando en 1935, mediante la Ley 68 convertirse en un organismo autónomo con personería jurídica e independencia (Semana, 2017):

Para agrupar las Facultades dispersas en el centro, diseñó y empezó a construir, en tierras que entonces quedaban a las afueras de Bogotá, el campus de la Ciudad Universitaria, conocida como la Ciudad Blanca (...) El arquitecto Leopoldo Rother diseñó, por primera vez en el país, un campus con amplias zonas verdes y de esparcimiento, enlazadas por senderos peatonales y dos vías perimetrales. Geometrías simples, carentes de aditamentos superfluos, que ofrecían un conjunto de vanguardia. La Universidad que conocemos hoy es, en lo fundamental, la concebida en 1935, con los ajustes y adecuaciones necesarios. En 1936 se incorporó la Escuela Nacional de Minas en Antioquia y dos años más tarde la Escuela de Agricultura Tropical de Medellín. Con esto comenzó oficialmente a operar la sede Medellín de la Universidad. De una forma parecida, los antecedentes de la sede Manizales se remontan a 1946, cuando el gobernador José Jaramillo Montoya y el rector Gerardo Molina promovieron su creación. Para el caso de la sede Palmira debemos recordar que se originó con la incorporación a la Universidad Nacional de la Escuela Superior de Agricultura Tropical en 1964 (pp. 1-3).

La Universidad Nacional en sus últimos 150 años ha sido un apoyo indispensable para la sociedad colombiana, al formar un número importante de profesionales para diversas áreas del conocimiento. Es difícil que un consumidor cotidiano no conozca la Universidad o no entienda su papel en el desarrollo de la sociedad colombiana, sin embargo, la imagen de la universidad ha pasado por muchos momentos: en julio de 1986 el doctor Roberto Rosero realizó un estudio (Rosero, 1986), que, entre otros, buscaba determinar la preferencia de los bachilleres por carreras y universidades, se realizó con 600 estudiantes de último año, con 20 colegios de cada nivel socioeconómico. En especial la investigación se centró en indagar sobre las preferencias de carrera y universidad con una pregunta central para conocer si el proceso de ingreso era determinante y era si el estudiante tuviera una beca que asumiera los costos de sus estudios universitarios, que centro universitario preferiría, en especial si este era público o privado, los resultados arrojaron una declinación de la preferencia por la Universidad Nacional, prefiriendo universidades privadas. 14 años después en el año 2000 en una alianza Napoleón Franco ${ }^{\circledR}$ y la Universidad Nacional se realizó una nueva investigación (Rosero, Montoya y Montoya, 2000), con un tamaño de muestra de 1203 encuestas de estudiantes de bachillerato de la ciudad de Bogotá, que buscaba conocer la percepción de la universidad nacional en este grupo poblacional cuya distribución se muestra en la Tabla 4.

TABLA 4.

Muestra de la investigación

\begin{tabular}{lclclc}
\hline \multicolumn{1}{c}{ Edad } & $\%$ & Estrato & $\%$ & Genero & $\%$ \\
\hline $14-16$ & $37 \%$ & Alto & $5 \%$ & Mujer & $47 \%$ \\
$17-19$ & $57 \%$ & Medio & $6 \%$ & Hombre & $53 \%$ \\
20 o más & $6 \%$ & Bajo & $89 \%$ & & \\
\hline
\end{tabular}

Fuente: Rosero, Montoya y Montoya, 2000, p. 13.

De nuevo la pregunta fue: Si tuviera una beca que pagara sus estudios, ¿en cuál Universidad estudiaría? Y se encontró que el 41 $\%$ de los bachilleres de la muestra elegiría la UN, de acuerdo con los atributos señalados en la Tabla 5. 
TABLA 5.

Atributos en diferentes universidades

\begin{tabular}{lccc}
\hline \multirow{2}{*}{\multicolumn{1}{c}{ Atributos }} & \multicolumn{3}{c}{ Universidad } \\
\cline { 2 - 4 } & Nacional & Javeriana & Andes \\
\hline El nivel y la exigencia académica son altos & 76 & 61 & 57 \\
La calidad de la educación es alta & 74 & 60 & 57 \\
La calidad de sus docentes es alta & 69 & 56 & 55 \\
Las facilidades para el pago de matrícula que ofrece son altas & 69 & 24 & 22 \\
La calidad de sus egresados en su desempeño profesional es alta & 67 & 54 & 49 \\
Los criterios y exigencias para admisión son altos & 65 & 47 & 49 \\
El reconocimiento de los egresados en el campo laboral es alto & 59 & 52 & 51 \\
La vinculación de sus egresados en el campo laboral es alta & 48 & 44 & 50 \\
El valor de la matrícula en cada universidad es alto & 13 & 72 & 83 \\
\hline
\end{tabular}

Fuente: Rosero, Montoya y Montoya, 2000, p. 15.

Este estudio determinó que los estudiantes preferirían en un 51\% las universidades privadas pero también se encontraron posiciones de rechazo como "sus estudiantes y profesores eran guerrilleros o comunistas" (Rosero, Montoya y Montoya, 2000, p. 17).

Estos resultados corroboran mucho la afectación que han tenido las universidades públicas colombianas con el programa gubernamental SER PILO PAGA, programa que paga al estudiante sus estudios con un crédito condonable en la universidad que éste decida seguir:

Tres años después de ponerse en marcha Ser Pilo Paga, sólo el 15,6 \% de los beneficiarios están matriculados en universidades públicas, el 83,8 \% lo están en universidades privadas y el $0,6 \%$ en instituciones de carácter especial. Las universidades privadas que más pilos reciben son: Javeriana (2.541, 8\%), La Salle (1.881, $6 \%$ ), los Andes (1.869, 6\%), Pontificia Bolivariana (1.741, 6\%) y Jorge Tadeo Lozano (1395,5\%). Los Andes es la tercera universidad que más pilos tiene, pero la que más plata recibe: $\$ 49.065 ’ 428.800$, casi el doble que la Bolivariana y La Salle (Correa \& Pardo, 2017).
Lo cual coloca a las universidades públicas en una situación de vulnerabilidad, ya que muchos de los nuevos estudiantes eligen privadas por el contacto social o por evitar el proceso de selección riguroso que tienen las universidades públicas del país. Otra creencia es que las universidades públicas exigen más lo que haría más difícil tener buenos promedios para conseguir la condonación del préstamo. Evaluar la imagen de la universidad resulta interesante también en este sentido y es como la comunidad del país ve a la universidad pública con mayor tradición (Carvajal, 2014).

En el 2011 las directivas de la universidad lanzaron el programa Orgullo $U N{ }^{\circledR}$ (Universidad Nacional, 2011) en donde se promocionan las personas que son un orgullo para la universidad y la comunidad en general por sus aportes en la academia, la investigación o el aporte a la comunidad, sus redes sociales son seguidas por más de 77.549 (Datos extraído del Facebook de la Universidad Nacional, 2019). Y 9.793 seguidores en Twitter al 31 de marzo de 2018. 


\section{Orgullo UN}

@Orgulloun

Generamos sentido de pertenencia entre la comunidad de la Universidad Nacional de Colombia \#SomosOrgulloUN

○) Colombia $\mathcal{S}$ orgulloun.unal.edu.co

\subsection{Seguidores}

Figura 4. Orgullo UN.

Fuente: Tomado de https://twitter.com/ OrgulloUN?lang=es

Por la importancia que reviste la Universidad Nacional de Colombia en sus 150 años de historia en el país, se ha tomado esta marca como modelo de valoración para el presente estudio:

La Universidad Nacional de Colombia no es solo historia, que de por sí es rica y fundamental para el país. Es presente serio y futuro promisorio. Esta institución pertenece a todos y ha sido construida gracias al aporte, el apoyo y el cariño de cada uno de los colombianos" (Semana, 2017).

La campaña Orgullo UN tuvo un gran éxito desde su inicio porque relacionó directamente la marca amor con la marca UN, buscando "resaltar la importancia de los proyectos, las investigaciones, los premios y las innovaciones que la Universidad Nacional de Colombia tiene para el mundo (Bolaños, 2010).

El 9 de junio el sitio web de la universidad comunico que ya eran 80.000 seguidores en Facebook (Figura 6).

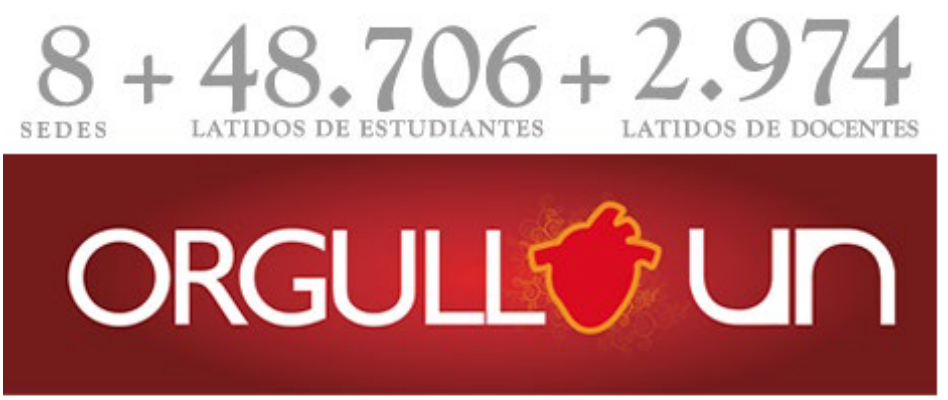

¿ Y tú, ya sientes Orgullo UN ?

Figura 5. Orgullo UN.

Fuente: Tomado de https://twitter.com/ OrgulloUN?lang=es

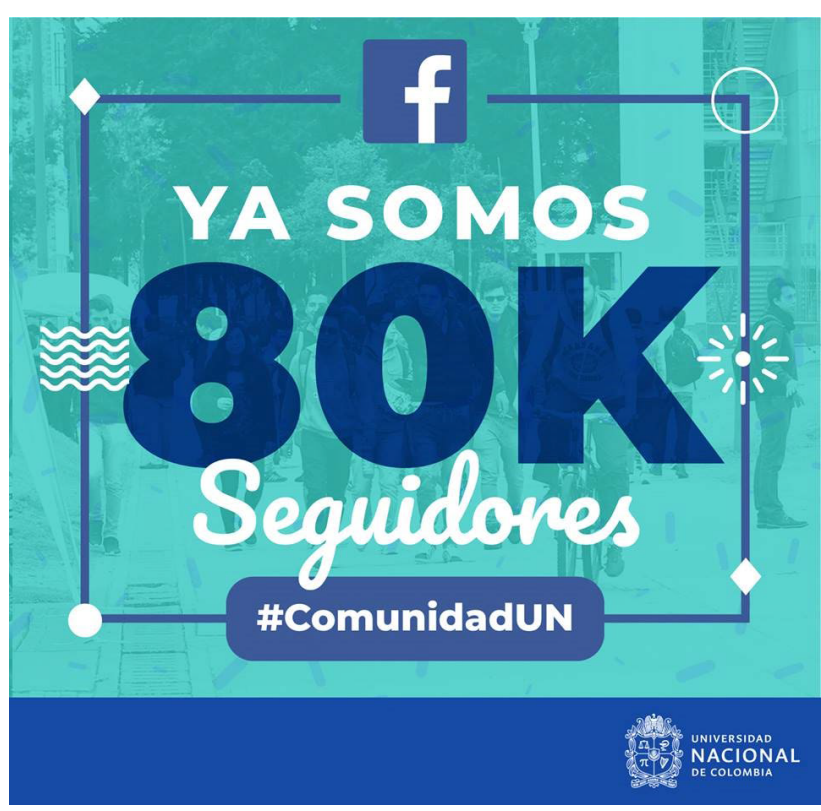

Figura 6. Seguidores en Facebook.

Fuente: Tomado de https://www.facebook.com/ UNColombia/photos/a.902826553066511.1073741 $828.902690903080076 / 2132904516725369 /$ type= $3 \&$ theater

\section{Metodologia}

Cho (2011), propuso el Desarrollo de una escala de imagen de marca en Lovemark basada en la propuesta de Roberts (2004). Se retomó este instrumento haciendo una traducción de este y aplicación a la marca no como un producto sino como el servicio, estas variables y sus preguntas se observan en la Tabla 6. 
TABLA 6.

Variables y preguntas adaptadas por Cho en el 2011

\begin{tabular}{|c|c|c|}
\hline Variable a evaluar & Preguntas & Autores \\
\hline Conciencia de marca & $\begin{array}{l}\text { Ya sé lo que significa esta marca. } \\
\text { Tengo una opinión sobre esta marca. } \\
\text { He oído hablar de esta marca. } \\
\text { Estoy al tanto de esta marca. } \\
\text { Con frecuencia pienso en esta marca. }\end{array}$ & $\begin{array}{l}\text { Keller (2008) } \\
\text { Aaker (1996) }\end{array}$ \\
\hline Amor a la marca & $\begin{array}{l}\text { Amo esta marca. } \\
\text { Esta marca me causa un asombro. } \\
\text { Esta marca es totalmente increíble. } \\
\text { Esta marca me hace sentir bien. } \\
\text { Esta es una marca maravillosa. }\end{array}$ & $\begin{array}{l}\text { Carroll \& } \\
\text { Ahuvia } \\
\text { (2006) }\end{array}$ \\
\hline Respeto a la marca & $\begin{array}{l}\text { Considero que es una marca de calidad. } \\
\text { Respeto esta marca. } \\
\text { Estoy muy comprometido con esta marca. } \\
\text { Esta marca se comunica bien conmigo. } \\
\text { Esta marca es honesta para mí. } \\
\text { Esta marca es responsable para mí. } \\
\text { Considero que tengo fidelidad a esta marca. } \\
\text { Esta marca es la preferida por todos. }\end{array}$ & $\begin{array}{l}\text { Frei and } \\
\text { Shaver } \\
(2002)\end{array}$ \\
\hline Misterio & $\begin{array}{l}\text { Esta marca agrega a la experiencia de mi vida. } \\
\text { Esta marca despierta buenos recuerdos para mí. } \\
\text { Esta marca captura la sensación de mi vida. } \\
\text { Esta marca captura los tiempos. } \\
\text { Esta marca me viene a la mente inmediatamente, } \\
\text { cuando pienso en una universidad pienso en esta marca. } \\
\text { Esta marca es parte de mi vida. }\end{array}$ & $\begin{array}{l}\text { (Roberts, } \\
2004,2006)\end{array}$ \\
\hline Sensualidad & $\begin{array}{l}\text { El diseño de los anuncios de esta marca está muy bien hecho. Ir } \\
\text { a los campus me atrae. } \\
\text { Cuando voy a otras ciudades en donde hay sedes las visito. } \\
\text { El diseño del sitio web para esta marca está muy bien hecho. } \\
\text { Entrar a sus edificaciones me atrae. } \\
\text { Esta marca tiene un hermoso esquema de colores. } \\
\text { Esta marca tiene una publicidad increíble. }\end{array}$ & $\begin{array}{l}\text { (Roberts, } \\
\text { 2004, 2006). } \\
\text { Bagozzi, } \\
\text { Batra \& } \\
\text { Ahuvia } \\
\text { (2014). }\end{array}$ \\
\hline Intimidad & $\begin{array}{l}\text { Puedo confiar en esta marca. } \\
\text { Me siento conectado con esta marca. } \\
\text { Me siento feliz cuando hablo de la marca. } \\
\text { Me siento satisfecho con esta marca. } \\
\text { Me divierto con esta marca. } \\
\text { Me siento orgulloso de esta marca. } \\
\text { Tengo un soporte sólido para esta marca. } \\
\text { Me gusta saber de profesionales de esta universidad. } \\
\text { Realmente disfruto mencionarla. } \\
\text { Me gustaría volver a conectar con la marca. }\end{array}$ & $\begin{array}{l}\text { (Roberts, } \\
\text { 2004). }\end{array}$ \\
\hline $\begin{array}{l}\text { Experiencia de la } \\
\text { marca }\end{array}$ & $\begin{array}{l}\text { Pienso mucho cuando encuentro esta marca. } \\
\text { Esta marca estimula mi curiosidad y resolución de problemas. }\end{array}$ & $\begin{array}{l}\text { Brakus, } \\
\text { Schmitt \& } \\
\text { Zarantello } \\
(2009)\end{array}$ \\
\hline
\end{tabular}


Elementos constructivos de la experiencia de marca

Involucramiento de la marca

Lealtad de marca

Valor general de marca

Búsqueda de información
Esta marca deja una fuerte impresión en mi sentido visual.

Esta marca deja una fuerte impresión en mis otros sentidos.

Encuentro esta marca interesante de una manera sensorial.

Esta marca no atrae mis sentidos.

Esta marca incluye sentimientos.

No tengo emociones fuertes para esta marca.

Esta marca es una marca emocional.

Esta marca es muy importante para mi.

Esta marca es muy relevante para mí. significa mucho para mí.

Es muy útil para mí.

Es Fundamental para mí.

Es una marca beneficiosa para mí.

Es una marca valiosa para mí.

Es una marca que despierta mi interés.

Es una marca emocionante.

Es una marca deseable.

Es una marca atractiva o agradable.

Me considero leal a esta marca.

Considero que esta es la única marca de universidad que me gusta.

Prefiero esta marca siempre que puedo.

Busco en las redes sociales tanto de esta marca como puedo.

Pertenezco a las redes sociales de la marca

Esta es la única marca que preferiría usar.

Haría un esfuerzo para usar esta marca.

Si esta marca no estuviera disponible, sería difícil para mi

Tiene sentido preferir esta marca en lugar de cualquier otra.

La prefiero, incluso con otras parecidas.

Esta marca no es diferente a la otras de las universidades. parece más inteligente preferir esta marca.

¿Has buscado la marca por algún motivo en páginas web?

¿Has visitados sus instalaciones?

(¿Eres parte de cualquier comunidad en línea que habla sobre esta marca?
Keller (2008)

Brakus.

Schmitt \&

Zarantello

(2009)

Zaichkowsky

(1985)

Yoo \& Donthu (2001)

Bloch, Sheller \& Ridgway (1986)

Fuente: Traducción y adaptación de Cho (2011).

Con estos propósitos se realizó el campo con la siguiente ficha técnica de la investigación (Tabla 7).

\section{REsultados}

Debido a que la aplicación de la encuesta se realizó mediante la creación de una página en Facebook con promoción en la misma, se encontraron dos tipos impor- tantes de respuestas, las de la encuesta propiamente dicha y mensajes y comentarios en los anuncios, estos segundos no se esperaban, pero las personas invitadas a responder la encuesta se sintieron en la necesidad de comentar el anuncio, la Figura 7 señala como el mensaje fue 95 veces compartido, con 866 me gusta y tan solo 3 me enoja, entre el 13 de febrero y el 131 de marzo de 2018. 
TABLA 7.

Ficha técnica de la investigación

\begin{tabular}{|c|c|}
\hline & ENCUESTA DE IMAGEN DE LA UNIVERSIDAD NACIONAL \\
\hline $\begin{array}{l}\text { Fecha de recolección de } \\
\text { información: }\end{array}$ & 13 de febrero -31 de marzo de 2018 \\
\hline Forma de recolección & $\begin{array}{l}\text { Encuesta online de Google: https://docs.google.com/forms/d/e/1FAIpQLSeH5 } \\
\text { MGmXjU1UZIHINOsf7I4iPICg2W_tPBlqhqeFEt55C2MPQ/viewform }\end{array}$ \\
\hline Página en facebook & $\begin{array}{l}\text { https://www.facebook.com/Encuesta-sobre-Imagen-Universidad-Nacional- } \\
\text { de-Colombia-208184909731954/inbox/?selected_item_id=100009805602244 }\end{array}$ \\
\hline Marco muestral & 17.000.000 usuarios mayores de 14 años en Facebook en Colombia \\
\hline Tamaño de la muestra & 265 \\
\hline Error & $6 \%$ \\
\hline Nivel de confianza & $95 \%$ \\
\hline
\end{tabular}

Fuente: Elaboración propia.

\section{Invitar a que indiquen que les gusta Encuesta sobre Imagen Universidad Nacional de Colombia}

Todas: 866 (1) 833 (2) 23 \& 5

Figura 7. Me gusta en la página web.

Fuente: Elaboración propia.

\section{Pertenece a la comunidad universitaria como...}

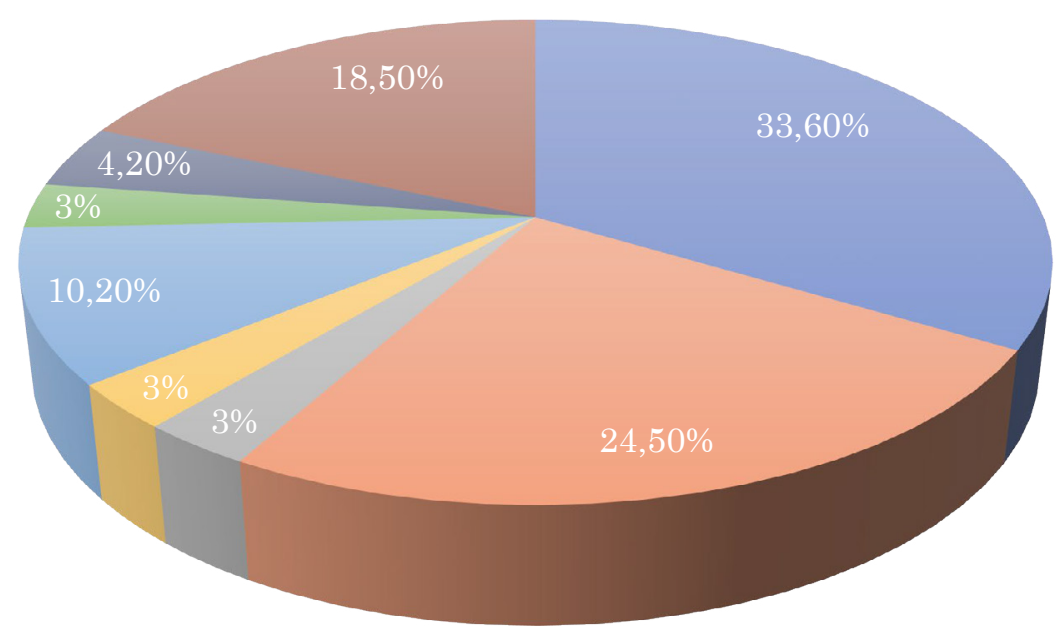

- Estudiante

Ex estudiante

- Pensionado

- Egresado

- Familiar de empleado o profesor

- Ninguna de las anteriores

Profesor

- Administrativo o trabajador

Figura 8. Pertenencia a la comunidad.

Fuente: Elaboración propia.

Los datos demográficos de la encuesta señalaron que el $41 \%$ son personas entre $18-25$ años y el 34\% entre 26 -40, el 65\% se encuentran en estrato 3-4. De los en- cuestados el $33.6 \%$ son estudiantes, $24.5 \%$ Egresados y solo el 10.2\% no tenían vinculo con la universidad y por tanto con la marca directamente (Figura 8). 
Las principales palabras que se reunieron en los conceptos dados por las personas espontáneamente, destacando conceptos como la mejor Universidad, excelente imagen, educación, buenos profesionales entre otros conceptos que señalaban calidad académica, prestigio y cariño por la universidad, que se pueden observar en la Figura 9.

El $80 \%$ de las respuestas señalaron saber lo que era la marca y el $75 \%$ dijo estar atento a las actividades que realizaba la marca.
He odio hablar de la marca en calificación de Likert 5 (74.7) y 5 (126.6\%), siguen la marca el $72 \%$. Aman la marca con calificación de 5177 personas, con un 55.5\%, $78 \%$ piensan entre 4 y 5 que la marca es increíble y en general la fidelidad 55\%, la responsabilidad $55.8 \%$, la marca genera experiencias en la vida con calificación de $555.8 \%$, buenos recuerdos 57.4\% (Calificación de 5) y se convierte en un top of mind con un $85 \%$.

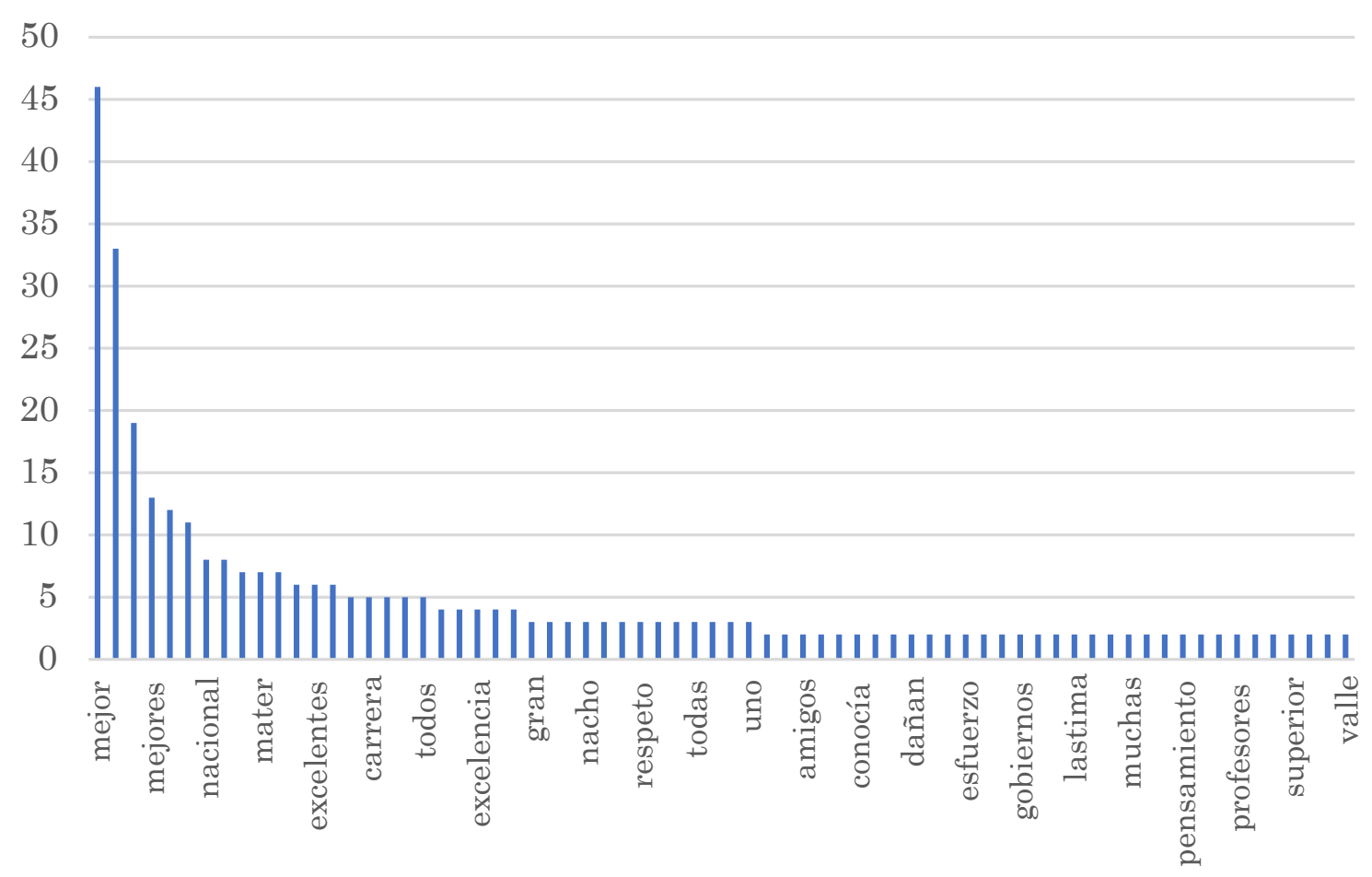

Figura 9. Principales menciones acerca de la Universidad.

Fuente: Elaboración propia.

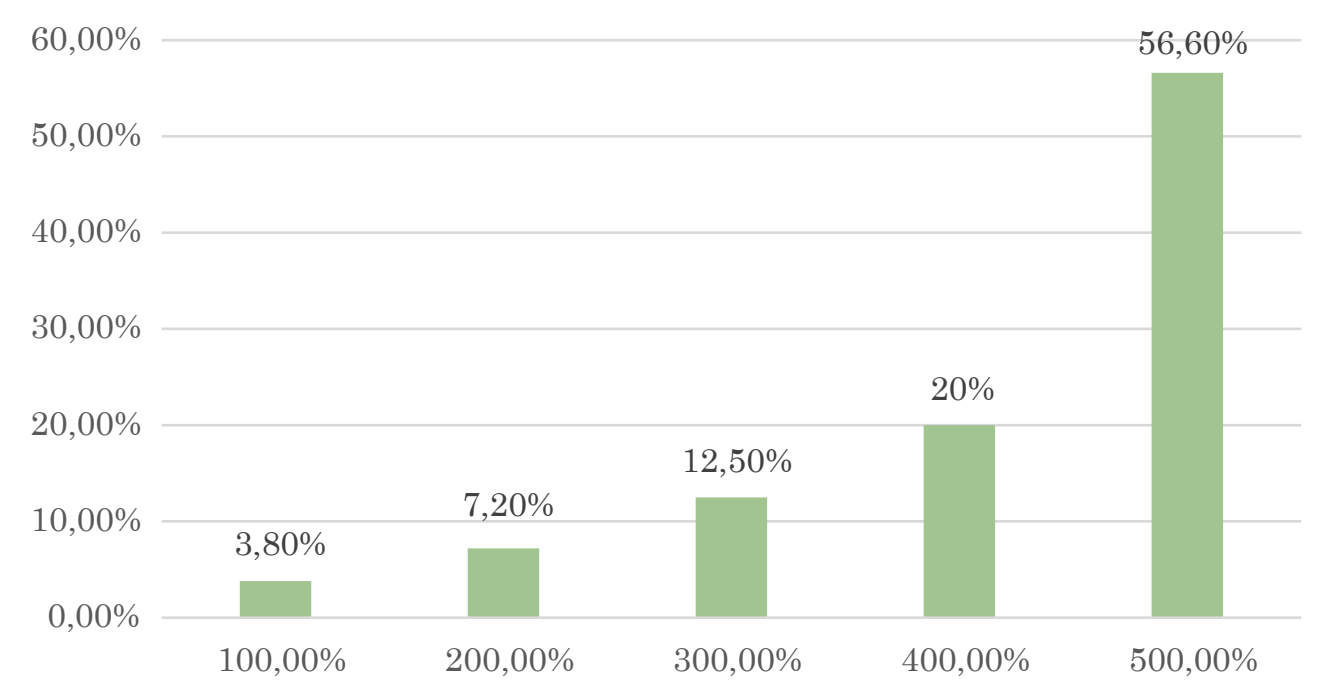

Figura 10. Respuestas de esta marca es parte de mi vida.

Fuente: Elaboración propia. 
Finalmente, las respuestas relacionadas se encuentran con un promedio de personas que señalaron una calificación de 5 en escala de Likert, para $56.3 \%$ y un $4 \%$ en promedio de $24.6 \%$, dando una calificación general de aprobación de $80.9 \%$ de las respuestas de los participantes. Permitiendo concluir que efectivamente la marca Universidad Nacional de Colombia es una marca amor.

\section{Conclusiones}

Para las marcas es importante entender cuál es su posicionamiento en la mente del consumidor, y en especial, en su corazón, existen diferentes escalas, pero tienen limitaciones, pocos investigadores además han medido el amor de una marca (Albert \& Valette-Florence, 2010, p. 61)

Utilizar escalas de amor ofrecen unas herramientas útiles para la gestión de marca, ya que identificar los consumidores permite entender las características que los vinculan con la marca (pasión o afecto) y así se pueden crear programas de fidelidad ajustados, publicidad que funcione porque responde a las necesidades de los consumidores (Albert \& Valette-Florence, 2010, p. 61).

En la investigación realizada se tomó como estudio de caso una universidad Colombiana, por su característica de ser una universidad reconocida en la sociedad, por el tiempo de funcionamiento y en especial por su peculiaridad de universidad pública, la cual, en especial presenta la ausencia de publicidad en todos los medios y sólo la difusión de mensajes especiales como admisiones o noticias de logros de la comunidad académica.

Como contribución a futuras investigaciones se proponen seguir indagando como se ha fortalecido la imagen, se encuentra que los egresados crean lazos importantes al sentirse parte del proceso, y los estudiantes se sienten un poco menos relacionados en la marca.

Empleados, profesores y administrativos en general, la tienen como una marca mejor posicionada, ello debido en parte también, a la calidad laboral alta que en general tiene la institución y que ha sido reconocida en diferentes estancias.

Se encontró con la metodología propuesta, que la marca Universidad Nacional de Colombia es una marca amor que se caracteriza por tener el cariño de los colombianos, con los tres elementos fundamentales de intimidad, sensualidad y misterio, además de tener el respeto de las personas no sólo por la tradición que le acompaña sino también por los resultados que se obtiene en docencia, investigación y extensión.

Debe realizarse más tipos de estos estudios, como dificultades especiales se encontró la baja participación de las personas en la encuesta a pesar de tener una motivación de premios por su participación, así como la necesidad de tener imágenes separadas de cada uno de los grupos de interés que se ven en la organización.

También seguir apropiando y desarrollando metodologías para la evaluación continua que permita ver como cambia la imagen de la organización y que actividades deben realizarse para fortalecerla.

\section{REFERENCIAS}

Aaker, D. A. (2007). Strategic market management. Hoboken: John Wiley.

Aaker, D. A. (1996). Measuring brand equity across products and markets. California Management Review, 38(3), 102-120. http://dx.doi.org/10.4236/ jmf.2018.81016

Aaker, D. A. (1992). Managing the most important asset: Brand equity. Planning Review, 20(5), 56-58. https://doi. org/10.1108/eb054384

Aaker, D. A. (1991). Managing brand equity: Capitalizing on the value of a brand name. New York: The Free Press.

Aaker, D. A. \& Biel, A. L. (2013). Brand equity \& advertising: advertising's role in building strong brands. London: Psychology Press. 
Aaker, J. L. (1997). Dimensions of brand personality. Journal of Marketing Research, 34(3), 347-356. https://doi. org/10.2307/3151897

Ahuvia, A. C. (2005). Beyond the extended self: Loved objects and consumers' identity narratives. Journal of Consumer Research, 32(1), 171-184. https://doi.org/10.1086/429607

Albert, N. \& Valette-Florence, P. (2010). Measuring the love feeling for a brand using interpersonal love items. Journal of Marketing development and Competitiveness, 5(1), 57-63.

Albert, N., Merunka, D. \& Valette-Florence, P. (2008). When consumers love their brands: Exploring the concept and its dimensions. Journal of Business Research, 61(10), 1062-1075. https:// doi.org/10.1016/j.jbusres.2007.09.014

Alvarado, K. y Lucano, A. (2015). Valor de marca: un acercamiento conceptual mediante su origen y modelos. Revista de Investigación Valor Agregado, 2(1), 21-32.

Andreassen, T. W., Kristensson, P., Lervik-Olsen, L., Parasuraman, A., McColl-Kennedy, J. R., Edvardsson, B. \& Colurcio, M. (2016). Linking service design to value creation and service research. Journal of Service Management, 27(1), 21-29.

Antequera, M. \& Lopes, E. (2016). No te he visto pero me acuerdo: Cómo se relacionan las personas con deficiencia visual con las marcas. [bachelor Thesis]. Universitat Autònoma de Barcelona, España. Disponible en https:// ddd.uab.cat/record/163929

Bagozzi, R. P., Batra, R. \& Ahuvia, A. C. (2017). Brand love: development and validation of a practical scale. Marketing Letters, 28(1), 1-14. https://doi. org/10.1007/s11002-016-9406-1

Bagozzi, R. P., Batra, R. \& Ahuvia, A. C. (2014). Brand Love: Construct Validity, Managerial Utility, and New Conceptual Insights. Working paper. University of Michigan, Ann Arbor, MI.
Ballester, M. E. D. (2004). Estado actual de la investigación sobre la lealtad a la marca: una revisión teórica. Dirección y Organización, (30), 16-24.

Batra, R., Ahuvia, A. C. \& Bagozzi, R. P. (2012). Brand love. Journal of marketing, 76(2), 1-16. https://doi.org/10.1509/ jm.09.0339

Blackett, T. \& Harrison, T. (2001). Brand Medicine: Use and Future Potential of Branding in Pharmaceutical Markets. Journal of Medical Marketing: Device, Diagnostic and Pharmaceutical Marketing, 2(1), 33-49. https://doi. org/10.1057/palgrave.jmm.5040053

Bloch, P., Sheller, D. \& Ridgway, N. (1986). Consumer Search: An Extended Framework. Journal of Consumer Researc, 13(1), 119-126.

Bolaños J. (2010). Unimedios Bogotá. [Online] . Disponible en http://www.cartauniversitaria.unal.edu.co/nc/detalle/ article/una-marca-que-da-orgullo-un/

Brakus, J., Schmitt, B. \& Zarantonello, L. (2009). Brand Experience: What Is It? How IsIt Measured? Does It Affect Loyalty? Journal of Marketing, 73(3), 52-68. https://doi.org/10.1509/ jmkg.73.3.52

Bristow, D. N., Schneider, K. C. \& Schuler, D. K. (2002). The brand dependence scale: Measuring consumers' use of brand name to differentiate among product alternatives. Journal of Product \& Brand Management, 11(6), 343-356. https:// doi.org/10.1108/10610420210445488

Carroll, B. A. \& Ahuvia, A. C. (2006). Some antecedents and outcomes of brand love. Marketing letters, 17(2), 79-89. https://doi.org/10.1007/s11002-006 4219-2

Carvajal, L. A. (2014). Análisis de la identidad organizacional y su influencia en la imagen de la Universidad Nacional de Colombia-Sede Bogotá. [Tesis Doctoral] Universidad Nacional, Bogotá, D.C., Colombia.

Chernatony, L. and McDonald, M. (2003) Creating Powerful Brands. London: Elsevier/Butterworth-Heinemann 
Chernev, A., Hamilton, R. \& Gal, D. (2011). Competing for consumer identity: Limits to self-expression and the perils of lifestyle branding. Journal of Marketing, 75(3), 66-82. https://doi. org/10.1509/jmkg.75.3.66

Cho, E. (2011). Development of a brand image scale and the impact of lovemarks on brand equity. [Graduate Theses and Dissertations. Paper 11962]. Iowa State University, Iowa city, USA. https://doi. org/10.31274/etd-180810-4450

Chumaceiro, A., Hernández, J. y Chirinos, E. (2016). Responsabilidad social universitaria, desarrollo sostenible y ciudadanía ambiental. Cuadernos de RSO, 4(1), 53-64. Disponible en https://ucu.edu.uy/sites/default/files/ facultad/fce/rso/cuadernos-de-rso-vol4-n1-chumaceiro.pdf

Chumaceiro, A., Hernández, J., Meléndez, Y. y Acurero, M. (2017). Responsabilidad universitaria y sociedad del conocimiento para la generación de competencias TIC. En, A. Chumaceiro, F. Ramos y J. Hernández (Ed). Procesos formativos para el siglo XXI. Cabimas: Fondo editorial UNERMB.

Çifci, S., Ekinci, Y., Whyatt, G., Japutra, A., Molinillo, S. \& Siala, H. (2016). A cross validation of Consumer-Based Brand Equity models: Driving customer equity in retail brands. Journal of Business Research, 69(9), 3740-3747. https://doi. org/10.1016/j.jbusres.2015.12.066

Colmenares, Ó, y Saavedra, J. (2007). Aproximación metodológica para medir el capital de marca. Caso: cadenas de farmacias en Venezuela. Cuadernos de Administración, 20(33), 203-228. Recuperado de https://revistas.javeriana.edu.co/index.php/cuadernos_admon/article/view/4094

Correa, P. \& Pardo, T. (abril 29, 2017). Los Andes, ¿la universidad pública más costosa del país? El Espectador [Online]. Disponible en https://www. elespectador.com/noticias/educacion/ los-andes-la-universidad-publica-mascostosa-del-pais-articulo-691584
Delgado, A. A., Ballester, M. E. y Pelaez, J. (2014). ¿Quién ama a las marcas? Determinantes personales y de Consumo. Revista Española de Investigación de Marketing ESIC, 18(1), 2-16. https:// doi.org/10.1016/S1138-1442(14)60002-4

Escobar-Farfán, M., Mateluna, C. y Araya, L. (2016). Evolución y descripción de los modelos de personalidad de marca en Latinoamérica. Dimensión empresarial, 14(2), 91-113. https://doi. org/10.15665/rde.v14i2.736

Forero, M. F. (2014). Determinación de la aplicabilidad del Brand Equity basado en el consumidor para el contexto colombiano. [Doctoral dissertation]. Universidad Nacional, Bogotá D.C., Colombia.

Frei, J. R. \& Shaver, P. R. (2002). Respect in close relationships: Prototype definition, self-report assessment, and initial correlates. Personal Relationships, 9(2), 121-139. https://doi.org/10.1111/14756811.00008

Fung So, K. K., King, C., Sparks, B. A. \& Wang, Y. (2016). The role of customer engagement in building consumer loyalty to tourism brands. Journal of Travel Research, 55(1), 64-78. https:// doi.org/10.1177/0047287514541008

Gallo, G. (2000). Posicionamiento; El caso Latinoamericano. Bogotá, D.C.: McGraw-Hill.

García, A. (2016). Marcas \& lovemarks. Un primer acercamiento a sus aspectos negativos y ocultos. [Tesis licenciatura]. Universidad de Valladolid, España. Disponible en: http://uvadoc.uva.es/ bitstream/10324/18133/1/TFG-N.457. pdf

González, R., Galeano, H. \& Trejos, L. (2015). Estados Unidos en la política exterior colombiana: ialiado incondicional? Económicas CUC, 36(1), 43-56. Recuperado de https://revistascientificas.cuc.edu.co/economicascuc/article/ view/672

Haigood, T. (2001). Desconstructing Brand Personality. Chicago: AMA Summer Educators Conference. 
Hammerschmidt, M. \& Donnevert, T. (2008). Brand Efficiency and Brand Relevance-Introducing and Linking both Concepts. AMA Winter Educators' Conference Proceedings, Vol. 20, Austin, Texas. http://dx.doi.org/10.2139/ ssrn.962240

Hernani, M. (2008). Percepción de la personalidad de una marca global y de valores: un estudio comparativo entre consumidores brasileños y peruanos. Contabilidad \& Negocios, 3(5), 44-54.

Kelemen, Z. (2013). Lovemarks or passion brands may create barriers to private labels in the digital age. Regional and Business Studies, 4(1-2), 1-12.

Keller, K. (2008). Strategic brand management. Building, measuring, and managing brand equity. New Jersey: Prentice Hall.

Keller, K. (1993). Conceptualising, measuring and managing customerbased brand equity. Journal of Marketing, 57(1), 1-22. https://doi. org/10.2307/1252054

Keller, K. L. \& Kotler, P. (2016). Marketing management. London: Pearson.

Kotler, P. (2001). Dirección de marketing. London: Pearson Education.

Lambin, J. J. \& Tesser, E. (2004). Marketing estrategico $y$ operativo: marketdriven management. Libri: McGrawHill.

Lee, M. Y., Kim, Y. K., Pelton, L., Knight, D. \& Forney, J. (2008). Factors affecting Mexican college students' purchase intention toward a US apparel brand. Journal of Fashion Marketing and Management: An International Journal, 12(3), 294-307. https://doi. org/10.1108/13612020810889263

Lindstrom, M. (2011). Brandwashed, el lavado de cerebro de las marcas. Bogotá, D.C.: Norma.

Malik, G. \& Guptha, A. (2013). Measuring 'Brand Love': Understanding the Attitude of Millennials towards Select Brands. Ushus-Journal of Business Management, 12(4), 1-30. https://doi. org/10.12725/ujbm.25.1
Martínez, J. A. (2014). La importancia del nombre de marca; revisión de la literatura. Redmarka. Revista académica de marketing aplicado, 1(12), 3-32. http://dx.doi. org/10.17979/redma.2014.01.012.4815

Montoya, A. Montoya, A. \& Castaño, J. (2016). Metodología de evaluación de brand equity bajo la perspectiva de las comunicaciones integradas de marketing y el Lovemark. Punto de Vista, 6(10). 9-34. http:// dx.doi.org/10.15765/pdv.v6i10.767

Munuera, J. L. (2001). Brand trust in the context of consumer loyalty. European Journal of Marketing, 35(11-12), 1238-1259.

Ostrovskaya, L. (2014). Influencia de los valores y antivalores de los consumidores en la tendencia a usar el nombre de marca. [Doctoral dissertation]. Universidad Miguel Hernández de Elche, España.

Park, C. W., Eisingerich, A. B., Pol, G. \& Park, J. W. (2013). The role of brand logos in firm performance. Journal of Business Research, 66(2), 180-187. https://doi. org/10.1016/j.jbusres.2012.07.011

Pavel, C. (2013). What is behind the lovemark concept? Calitatea, 14(2), 482.

Pritchard, M. P. \& Howard, D. R. (2015). Measuring loyalty in travel services: A multi-dimensional approach. In, M. J. Sirgy, K. D. Bahn, T. Erem (ed.) Proceedings of the 1993 World Marketing Congress (pp. 120-124). Cham: Springer.

Roberts, K. (2006). The lovemarks effect: Winning in the consumer revolution. New York: Powerhouse Books.

Roberts, K. (2005). Lovemarks: El futuro más allá de las marcas. Urano (in Spanish).

Roberts, K. (2005). Lovemarks: The future beyond brands (2 ed.). New York: Powerhouse Books.

Roberts, K. (2004). Lovemarks: The future beyond brands (1 ed.). New York: Powerhouse Books.

Rosero, R. (1986). Preferencia de universidades y programas de bachilleres en la ciudad de Bogotá. Bogotá, D.C.: Unisabana.

Rosero, R. Montoya A. Montoya I. y Montañez G. (2000). Estudio de la universidad nacional, modalidad bachilleres. Bogotá, D.C.: Universidad Nacional. 
Schembri, S., Merrilees, B. \& Kristiansen, S. (2010). Brand consumption and narrative of the self. Psychology \& Marketing Journal, 27(6), 623-637. http://dx.doi.org/10.1002/ mar. 20348

Semana. (2017). La UN en la vida del pais. [Online]. Disponible en https://especiales.semana.com/universidad-nacional/index.html

Sproles, E. K. \& Sproles, G. B. (1990). Consumer decision-making styles as a function of individual learning styles. Journal of Consumer Affairs, 24(1), 134-147. https://doi. org/10.1111/j.1745-6606.1990.tb00262.x

Universidad Nacional. (2011). Mineducación reconoce a la UNAL en la Noche de los Mejores. [Online]. Disponible en http://orgulloun.unal.edu.co/

Universidad Nacional. (2019). Facebook Universidad Nacional. [Online]. Disponible en https://www.facebook.com/ UNColombia/?rf=109253625759997

Temporal, P. y Lee, K. (2003). Branding de alta tecnología. México, D.F.: McGraw Hill Interamericana.

Thomson, M., MacInnis, D. J., \& Whan Park, C. (2005). The ties that bind: Measuring the strength of consumers' emotional attachments to brands. Journal of consumer psychology, 15(1), 77-91. https://doi. org/10.1207/s15327663jcp1501_10

Villasmil, M. \& Crissien, T. (2015). Cambio de paradigma en la gestión universitaria basado en la teoría y praxis de la reingeniería. Económicas CUC, 36(1), 245-274. http:// dx.doi.org/10.17981/econcuc.36.1.2015.29

Yoo, B. \& Donthu, N. (2001). Developing and validating a multidimensional consumer-based brand equity scale. Journal of business research, 52(1), 1-14. https://doi. org/10.1016/S0148-2963(99)00098-3

Zarantonello, L. \& Schmitt, B. H. (2010). Using the brand experience scale to profile consumers and predict consumer behaviour. Journal of Brand Management, 17(7), 532-540. https://doi.org/10.1057/bm.2010.4

Zaichkowsky, J. (1985). Measuring the Involvement Construct. Journal of Consumer Research, 12(3), 341-352. http://dx.doi. org/10.1086/208520

\section{Biodata}

Luz Alexandra Montoya Restrepo es Doctora en Ciencias Económicas de la Universidad Nacional (Colombia). Pasantía de Doctorado en Ciencias Económicas de la Universidad Autónoma Metropolitana (Colombia). Magíster en Administración de la Universidad Nacional de Colombia. Administradora de Empresas de la Universidad Nacional de Colombia con Tesis Laureada. https://orcid.org/0000-0002-4896-1615

Javier Sánchez Torres es Doctor en Negocios con Maestría en Investigación y gestión deportiva, varios cursos de expertos universitarios en marketing y periodismo. Investigador en marketing, comercio electrónico e Internet (Universidad de Barcelona). Profesor de la Universidad de Medellín (Colombia). https://orcid.org/0000-0002-8217-2177

Sandra Patricia Rojas-Berrio tiene Doctorado en Ciencias Administrativas de la Instituto Politécnico Nacional de Mexico (México). Maestría en Administración de la Universidad Nacional de Colombia (sede Bogotá). Administradora de Empresas de la Universidad Nacional de Colombia (sede Bogotá). https://orcid.org/0000-0002-1148-3779

Juan Manuel Castaño-Molano tiene Maestría en Administración con Énfasis en Mercadeo del Instituto Tecnológico de Estudios Superiores de Monterrey-UNAB (México). Egresado en Economía Empresarial de la Universidad Autónoma de Manizales (Colombia). https://orcid.org/0000-00019654-1597

Ivan Alonso Montoya-Restrepo es Doctor en Ciencias Económicas de la Universidad Nacional de Colombia. Perfeccionamiento en Doctorado en Ciencias Sociales de la Universidad Autónoma Metropolitana. Magíster en Administración de la Universidad Nacional de Colombia y Administrador de Empresas de la misma universidad. https:// orcid.org/0000-0003-0959-3466 